\title{
DELIBERATE SELF-POISONING IN THE OXFORD AREA*
}

\author{
BY
}

JOHN GRIMLEY EVANSt

The Oxford Record Linkage Study

Self-poisoning, to use the term coined by Kessel, McCulloch, and Simpson (1963), is a common reason for emergency admission to hospital. Such episodes are frequently designated as attempted suicide but, as Stengel and Cook (1958) and others have pointed out, the impulse towards self-destruction may be only a minor factor in the motivation. Although there have been many psychiatric and clinical studies of self-poisoning, it has received less attention as a problem for social and preventive medicine.

This is a study of cases of self-poisoning admitted to hospitals in the area of the Oxford Record Linkage Study (ORLS). ORLS comprises a central file based on local sources, which collects abstracts of domiciliary midwifery records, birth and death certificates, and all types of hospital admissions relating to persons resident within a defined area. (Acheson, 1964; Acheson and Evans, 1964.) The file is linked so that data referring to the same individual but arising from different sources and at different times are brought together. It is therefore possible to reduce "events" to "persons", and to relate these to a population of known size and constitution.

\section{Material and Methods}

For the purpose of the study, self-poisoning was defined as the deliberate acute self-administration of a drug or poison with the intention of causing or risking death or harm, or in order to give the impression of such intention. In doubtful cases

- Requests for reprints should be addressed to the Oxford Record Linkage Study, Old Road, Headington, Oxford.

† Present address: Research Fellow in Clinical Epidemiology, Medical Unit, Wellington Hospital, New Zealand. the recorded opinion of the responsible clinician was to be accepted.

The primary material consisted of the hospital admission data collected by ORLS for the years 1962 to 1965 inclusive. This was accessible in the form of 80-column punch cards which were searched mechanically to extract and print out records bearing diagnoses N960 to N979 inclusive (Effects of Poisons) of the International Statistical Classification of Diseases. For the first 2 years data for all ages were retrieved. On inspection of the age distribution of the 638 admissions so obtained, two clearly demarcated groups were apparent. A childhood group of 239 admissions up to the age of 7 with modal age 2 years was distinct from an adolescent and adult group of which the youngest were aged 12. There were no cases aged 8 to 11 years inclusive. The notes of the five cases aged 6 and 7 years were inspected and confirmed as being accidental poisonings. No further study was made of cases aged under 10 years.

The notes of the 909 admissions involving persons aged 10 years and older during the 4 years were searched for at the six hospitals concerned. In ten instances ( $1 \cdot 1$ per cent.) the notes could not be traced and these were excluded from the study. Further exclusions were:

(1) Students and members of the Armed Forces not normally resident in the area (33 admissions).

(2) Cases not satisfying the criteria of self-poisoning (99 admissions). These comprised 22 admissions due to chronic drug toxicity, seven due to industrial exposure, five involving alcoholism, four patients overcome by smoke in a house fire, three cases of drug idiosyncrasy, two 
miscoded diagnoses, and four cases in which the poison had been administered by another person. One fatal case was excluded as an open verdict was returned at the inquest. The remaining 51 admissions rejected were due to acute self-poisoning considered by the responsible clinician to have been accidental.

The final material of the study consisted of the hospital notes of 767 admissions of 702 persons*. Information about management and disposal was abstracted and each case was graded according to

* As a corollary to accepting the clinician's opinion, the study group includes eleven admissions in which the patient denied deliberate self-poisoning. Ten of these cases were seen by a psychiatrist who agreed with the physician's assessment and the eleventh was known to have made a definite previous suicidal attempt. clinical severity. Owing to the retrospective nature of the study, grading had to be based on information $O$ that was likely to be recorded in the majority of $z$ cases. A preliminary survey suggested that most $\stackrel{\mathbb{Q}}{\circ}$ of the non-fatal cases could be allotted to one of three groups:

Grade 0: The patient was recorded as showing no effects attributable to the alleged poison ["Mild cases"].

Grade 1: The patient showed effects of the poison but no treatment was recorded other ${ }^{\circ}$ than gastric lavage, nursing care, and sedation.

Grade 2: One or more of the following treatments were recorded: injection of anti-hypotensive or

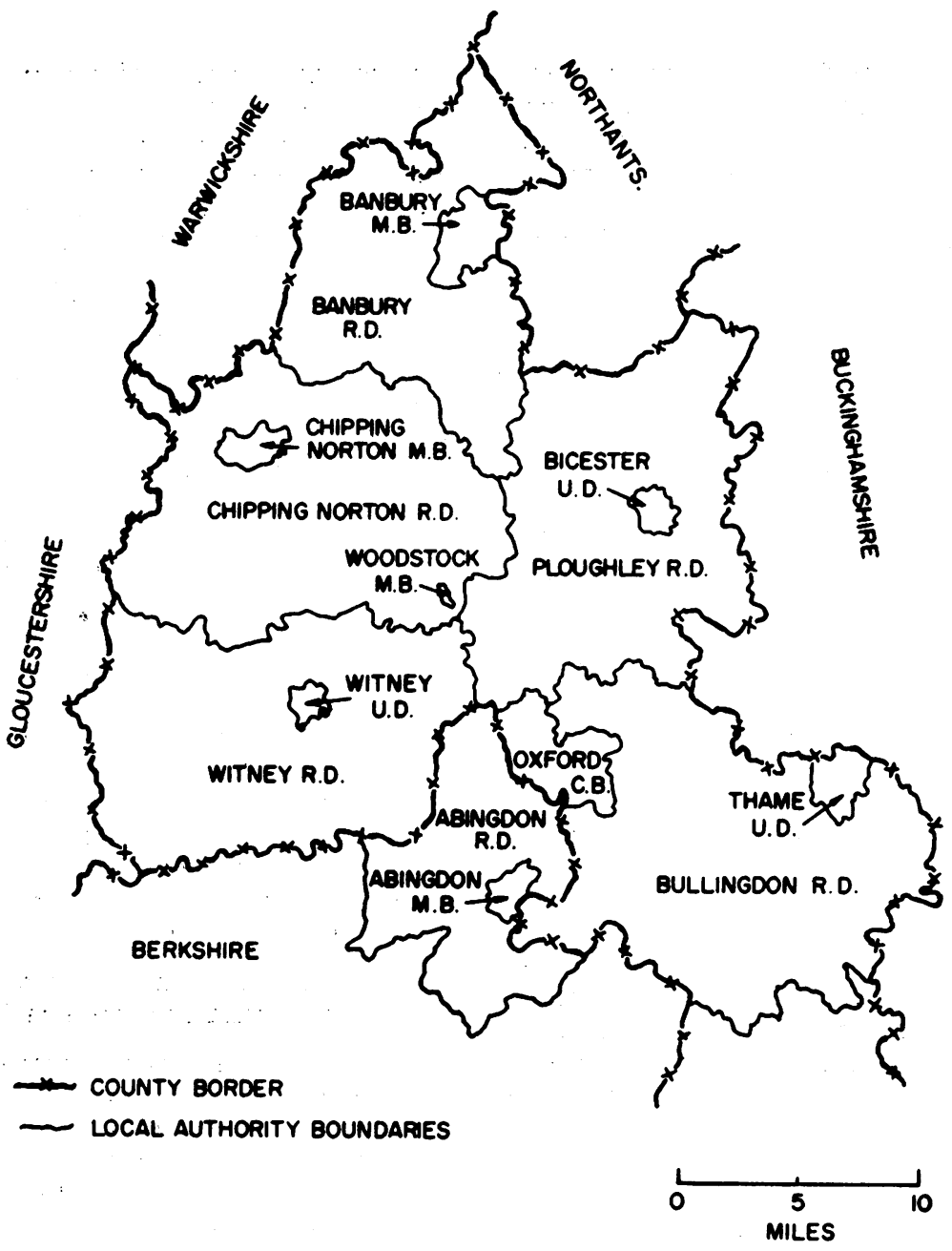

Fig. 1.-Oxford Record Linkage Study area. 
anti-convulsant drugs, intravenous infusion, endotracheal intubation, catheterization, peritoneal or haemodialysis, artificial respiration ["Severe cases"].

The Record Linkage Study Area consists of Oxford County Borough and thirteen surrounding Local Authority areas of Oxfordshire and Berkshire (Fig. 1). Information about the population was derived from the County Reports of the 1961 Census, with the assumption that the 1951-61 intercensal population increase of 1 per cent. per year had continued. The Census population for Oxford C.B. was reduced by 4,000 single males in the 20 to 24-year age group to correct for the undergraduates of the University who were in residence on Census Day. This correction was necessarily incomplete and was based on the results of the 1951 Census (when Census Day fell outside University Term) and on estimates from the University Registry.

According to context, results were calculated either in terms of events as admission rates, or in terms of persons as period prevalence rates.

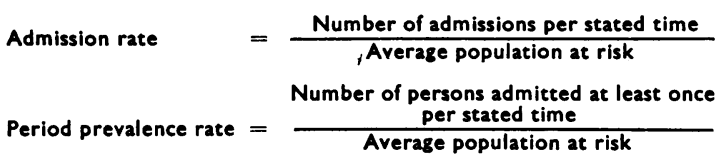

Two forms of period prevalence have been used. In the calculation of annual rates, a person is counted once (and once only) for each year in which he was admitted. This measure can be used to compare results from other areas and at other times. In the calculation of a 4-year prevalence rate, any person admitted is counted only: once for the whole study period. This measure is free from distortion due to multiple admissions and can be used for intra-study comparisons.

\section{RESULTS}

502 females and 200 males were admitted during the 4 years. The youngest subject was aged 11 and the oldest 85 years. Age and sex distributions. of the subjects are set out in Table IA. There were forty double admissions, seven triple, two quadruple, and one sextuple. Crude mean annual admission and prevalence rates, and 4-year prevalence rates are shown in Table IB.

NATURE of Poison.-The main poisons used were barbiturates (45 per cent. of all admissions) and aspirin ( 26 per cent. of all admissions). Domestic gas accounted for only 3 per cent. The relative proportions of poisons used were constant over the 4 years and there was no significant difference between the sexes. Variations with age were similar to those observed by Kessel (1965) in Edinburgh. The relative frequency of barbiturates rose steadily with age from 23 per cent. of admissions under the age of 20 to 60 per cent. of those aged 50 and over. Over the same age range the use of aspirin fell steadily from 49 to 12 per cent. The trend with domestic gas was much less regular owing to small numbers, but there was a relatively higher proportion of cases in the older age groups than in the younger.

TABLE IA

AGE AND SEX DISTRIBUTION OF SUBJECTS AND MEAN ANNUAL PREVALENCE RATES

\begin{tabular}{|c|c|c|c|c|c|c|c|c|c|c|c|c|c|c|c|c|}
\hline & \multirow{2}{*}{\multicolumn{2}{|c|}{ Sex }} & \multicolumn{13}{|c|}{ Age (yrs) } & \multirow{2}{*}{$\begin{array}{l}\text { Total } \\
\text { Subjects }\end{array}$} \\
\hline & & & $10-14$ & $15-19$ & $20-24$ & $25-29$ & $30-34$ & $35-39$ & $40-44$ & $45-49$ & $50-54$ & $55-59$ & $60-64$ & $65-69$ & 70- & \\
\hline No. of Subjects . . & $\begin{array}{l}\text { Male } \\
\text { Female }\end{array}$ & $\because$. & $\begin{array}{r}2 \\
10\end{array}$ & $\begin{array}{l}23 \\
87\end{array}$ & $\begin{array}{l}45 \\
73\end{array}$ & $\begin{array}{l}27 \\
79\end{array}$ & $\begin{array}{l}14 \\
53\end{array}$ & $\begin{array}{l}25 \\
44\end{array}$ & $\begin{array}{l}17 \\
43\end{array}$ & $\begin{array}{l}10 \\
29\end{array}$ & $\begin{array}{l}10 \\
28\end{array}$ & $\begin{array}{l}12 \\
13\end{array}$ & $\begin{array}{r}8 \\
20\end{array}$ & $\begin{array}{l}2 \\
9\end{array}$ & $\begin{array}{r}5 \\
14\end{array}$ & $\begin{array}{l}200 \\
502\end{array}$ \\
\hline $\begin{array}{l}\text { Mean Annual } \\
\text { Prevalence Rate* }\end{array}$ & $\begin{array}{l}\text { Male } \\
\text { Female }\end{array}$ & $\begin{array}{l}. \\
.\end{array}$ & $\begin{array}{r}4 \\
20\end{array}$ & $\begin{array}{r}47 \\
191\end{array}$ & $\begin{array}{r}84 \\
160\end{array}$ & $\begin{array}{r}56 \\
197\end{array}$ & $\begin{array}{r}36 \\
138\end{array}$ & $\begin{array}{r}56 \\
106\end{array}$ & $\begin{array}{r}45 \\
115\end{array}$ & $\begin{array}{l}21 \\
72\end{array}$ & $\begin{array}{l}23 \\
65\end{array}$ & $\begin{array}{l}31 \\
41\end{array}$ & $\begin{array}{l}29 \\
62\end{array}$ & $\begin{array}{l}25 \\
33\end{array}$ & $\begin{array}{l}16 \\
27\end{array}$ & \\
\hline
\end{tabular}

TABLE IB

SPECIFIED RATES, BY SEX

\begin{tabular}{|c|c|c|c|c|c|c|c|c|c|}
\hline \multirow{2}{*}{\multicolumn{3}{|c|}{$\frac{\text { Sex } \quad \cdots \quad \cdots}{\begin{array}{l}\text { Mean Annual } \\
\text { Prevalence Rate* }\end{array}}$}} & \multirow{2}{*}{$\cdots$} & \multicolumn{2}{|c|}{ Male } & \multicolumn{2}{|c|}{ Female } & \multicolumn{2}{|c|}{ All Persons } \\
\hline & & & & 31 & (4) & 80 & (7) & 56 & (4) \\
\hline \multicolumn{4}{|c|}{$\begin{array}{l}\text { Mean Annual } \\
\text { Admission Rate* }\end{array}$} & 33 & (5) & 84 & (7) & 59 & (4) \\
\hline \multicolumn{4}{|c|}{ 4-year Prevalence Rate† } & 123 & (4) & 306 & (7) & 215 & (4) \\
\hline
\end{tabular}

* Per 100,000 per year. † Per 100,000 per 4 years. Figures in brackets are standard errors.
Secular Changes.-As shown in Table II, the annual prevalence rates increased for both sexes

TABLE II

ANNUAL PREVALENCE RATES PER 100,000 BY YEAR

\begin{tabular}{|c|c|c|c|c|c|}
\hline \multicolumn{3}{|c|}{ Year } & Males & Females & All Persons \\
\hline $\begin{array}{l}1962 \\
1963 \\
1964 \\
1965\end{array}$ & $\begin{array}{l}\cdots \\
\cdots \\
\cdots\end{array}$ & $\begin{array}{l}\ddot{*} \\
\ddot{*}\end{array}$ & $\begin{array}{l}24 \\
31 \\
31 \\
40\end{array}$ & $\begin{array}{l}58 \\
82 \\
87 \\
94\end{array}$ & $\begin{array}{ll}41 & (4) \\
57 & (4) \\
59 & (4) \\
67 & (4)\end{array}$ \\
\hline
\end{tabular}

Figures in brackets are standard errors. 
over the 4 years. This was not due to changes in hospital admission policy. A review was made of the records of the Casualty Emergency Department of the Radcliffe Infirmary where 90 per cent. of the admissions in each year occurred. Of all poisonings of persons aged 10 years and over presenting to the Department in 1962 and 1963, 87 per cent. were admitted compared with 89 per cent. in 1964 and 1965. Admission of cases presented at the other hospitals in the study is probably 100 per cent. The increase in prevalence rate did not affect all age and sex groups equally. Comparison of the first and second halves of the study period showed proportionately greater increases among younger women and older men. The increase in mean annual prevalence rate for persons aged 40 and over was 74 per cent. for men and 6 per cent. for women, while for persons aged under 40 the increases were 11 per cent. for men and 48 per cent. for women. This difference between the sexes was seen for both urban and rural areas of residence (vide infra).

Fig. 2 depicts the experience of the 4 years in terms of events. There appears to be a tendency to relatively higher rates in the mid-part of each year. Both sexes contribute to this pattern. Over the 4 years significantly more admissions $(P<0.05)$ occurred in the second and third quarters of the year than in the first and fourth. This finding is difficult to interpret. In early August, 1962, and again in early August, 1963, when the highest admission rates for those years occurred, there were internationally publicized cases of suicide by $c$ self-poisoning. A much-publicized death by self- $O$ poisoning occurred in Oxford in the middle of May, 3 1965, and the following month showed the highest $\mathbb{8}$ admission rate of the whole study period. It seems likely that the apparent seasonal effect was pro- $\stackrel{\vec{D}}{\rightarrow}$ duced by imitative behaviour or other mechanisms $O$ following these events, but further observation is necessary to decide this. The possible implications for a preventive programme are obvious.

SEVERITY.- In the majority of cases the adopted $\%$ classification was easy to apply. It is unlikely to $\overrightarrow{0}$ have achieved sharp separation of grades of severity $\overrightarrow{\vec{H}}$ owing to different treatment regimes adopted by $\vec{\omega}$ clinicians and to variable standards of note-keeping. For fifty admissions (6.5 per cent.) the notes were $ᄋ$ not adequate to permit classification.

Table III shows that there were slightly more mild $\dot{\omega}$

TABLE III

SEVERITY, ALL ADMISSIONS

\begin{tabular}{|c|c|c|c|c|c|c|}
\hline \multirow{2}{*}{\multicolumn{3}{|c|}{ Severity }} & \multicolumn{2}{|c|}{ Males } & \multicolumn{2}{|c|}{ Females } \\
\hline & & & \multirow{2}{*}{$\begin{array}{r}\text { No. } \\
37 \\
138 \\
24\end{array}$} & \multirow{2}{*}{$\begin{array}{c}\text { Per cent. } \\
18 \cdot 4 \\
68 \cdot 7 \\
11 \cdot 9\end{array}$} & \multirow{2}{*}{$\begin{array}{r}\text { No. } \\
115 \\
345 \\
50\end{array}$} & \multirow{2}{*}{$\begin{array}{l}\text { Per cent. } \\
22 \cdot 3 \text { อ } \\
66 \cdot 8 \text { 은 } \\
9 \cdot 7 \leq\end{array}$} \\
\hline $\begin{array}{l}\text { Grade } 0 \\
\text { Grade } 1 \\
\text { Grade } 2\end{array}$ & $\begin{array}{l}\cdots \\
\cdots\end{array}$ & $\begin{array}{l}\cdots \\
\cdots \\
\cdots\end{array}$ & & & & \\
\hline Died & $\cdots$ & $\cdots$ & 2 & $1 \cdot 0$ & 6 & $1 \cdot 2 \frac{0}{2}$ \\
\hline \multicolumn{2}{|c|}{ Total } & .. & 201 & $100 \cdot 0$ & 516 & $100 \cdot 0$ \\
\hline \multicolumn{2}{|c|}{ Unclassified } & . & 17 & & 33 & \\
\hline
\end{tabular}

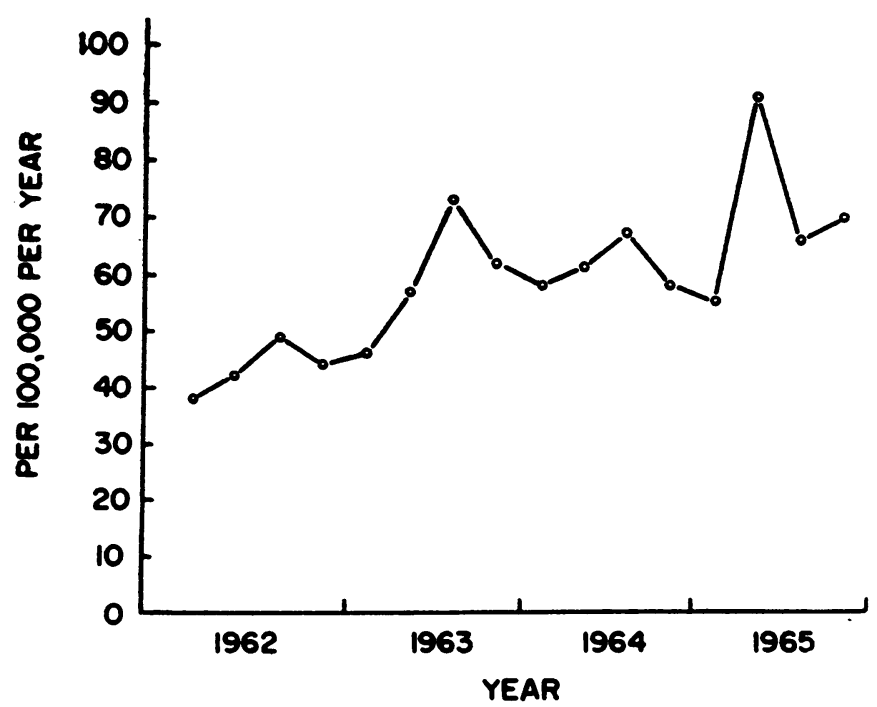

Fio. 2.-Crude admission rates for both sexes, by quarterly periods, 1962 to 1965. 
cases among females than among males. Severity grading showed no significant variation with year of admission. In particular, there was no suggestion that the rising prevalence over the period was associated with an increased referral of mild cases to hospital.

When the "seasonal" fluctuation is analysed in this way (Fig. 3), there is again no evidence that high rates are due to increased referral

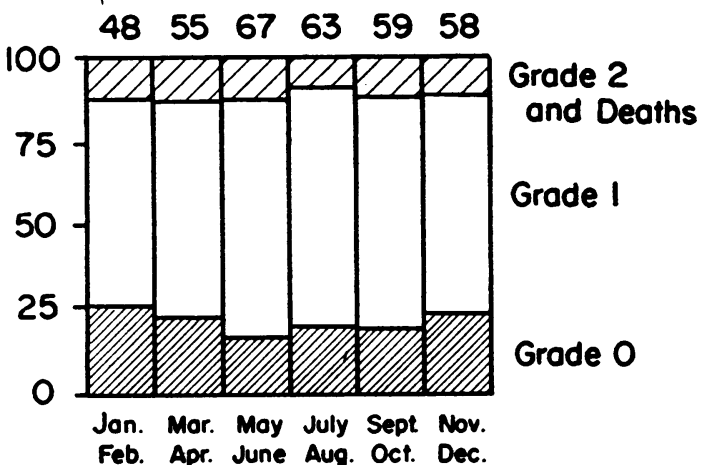

Fig. 3.-Severity grade percentages by month of admission. The figure above each bar is the corresponding mean prevalence rate per 100,000 per year corrected for secular trend. of mild cases. In fact, the increasing rates in the middle of the year are associated with a fall in the proportion of mild cases, although in July and August there is a reduction of about 5 per cent. in the proportion of severe cases.

Age AND Sex.-Age- and sex-specific mean annual prevalence rates are shown in Table $I$ and Fig. 4. Except in old age (75 years and older) the female rate is higher than the male, but both curves show maxima in early adult life. Thereafter the rate falls in females but in males levels out above the age of 45 .

Marital Status.-This was recorded for 691 of the 702 persons admitted. A comparison with the marital status distribution of the total population is presented in Table IV. The observed number in each group is compared with the number to be expected if the patients were an age-adjusted sample of the population at risk. An excess of the divorced and separated is seen in both sexes. When age- and sex-specific prevalence rates are plotted for married and single persons, further points of interest emerge. The highest rate of 1,640 per 100,000 per 4 years $(N=14)$ is found among

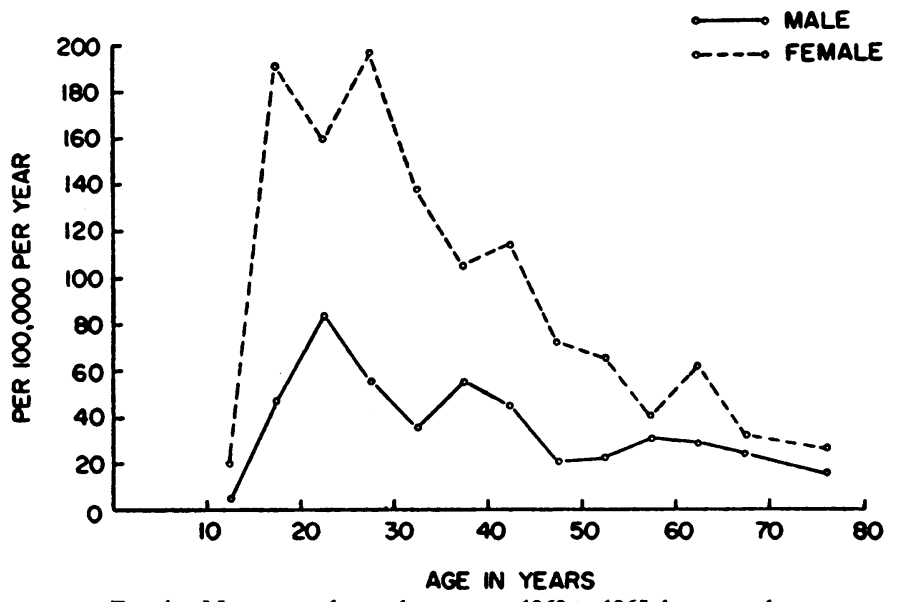

Fig. 4.-Mean annual prevalence rates, 1962 to 1965 , by age and sex.

TABLE IV

MARITAL STATUS, ALL PERSONS, BY SEX

\begin{tabular}{|c|c|c|c|c|c|c|c|c|}
\hline & Sex & & Single & Married & Widowed & $\begin{array}{l}\text { Divorced and } \\
\text { Separated }\end{array}$ & Total & Unclassified \\
\hline Male & $\begin{array}{l}\text { No. observed } \\
\text { No. expected }\end{array}$ & $\ddot{*}$ & $\begin{array}{l}84 \\
81 \cdot 1\end{array}$ & $\begin{array}{l}90 \\
110 \cdot 1\end{array}$ & $\begin{array}{l}6 \\
2 \cdot 9\end{array}$ & 15 & $\begin{array}{l}195 \\
195 \cdot 0\end{array}$ & 5 \\
\hline Female & $\begin{array}{l}\text { No. observed } \\
\text { No. expected }\end{array}$ & $\ddot{*}$ & $\begin{array}{l}145 \\
168 \cdot 1\end{array}$ & $\begin{array}{l}298 \\
302 \cdot 5\end{array}$ & $\begin{array}{l}24 \\
21 \cdot 6\end{array}$ & $\stackrel{29}{3 \cdot 8}$ & $\begin{array}{l}496 \\
496 \cdot 0\end{array}$ & 6 \\
\hline
\end{tabular}

* Based on Oxfordshire 1961 Census population age adjusted by quinquennial groups age 10 to 75. 


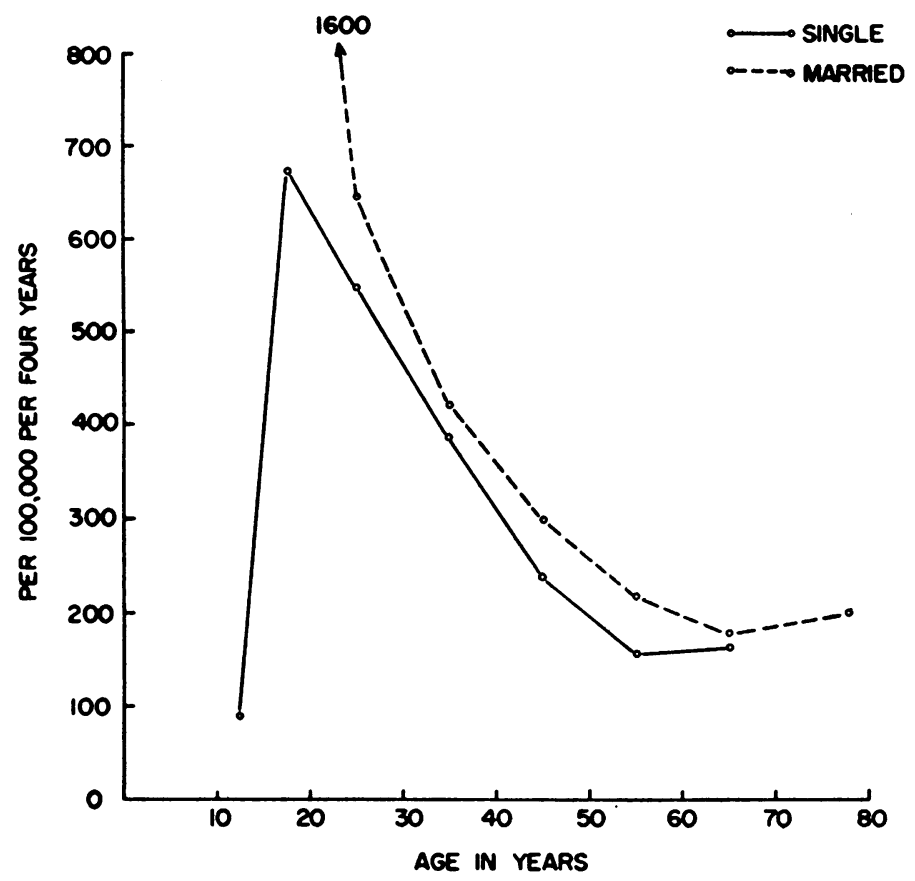

Fig. 5.-4-year prevalence rates for females, by age and marital status. (Age grouping by decades, except for ages 10 to 14 and 15 to 19 years. Widowed, divorced, and separated not included.)

married females under age 20 (Fig. 5); that for unmarried girls aged 15 to 19 was 668 per 100,000 per 4 years $(\mathrm{N}=73)$-a significant difference $(\mathrm{P}<0.03)$. The corresponding mean annual prevalence rates were 480 per year for married girls $(\mathrm{N}=17)$ and 171 per 100,000 per year $(\mathrm{N}=73)$ for the unmarried. One would like to know whether this very high rate among teenage wives is a consequence of, or cognate with, early marriage. It is unlikely to be an error attributable to an underestimate of the population at risk unless the number of teenage wives in the region increased suddenly between 1961 and 1962, since high annual rates for this group were seen from the start of the $\frac{3}{3}$ study period. Married women show slightly higher rates than single women at all other ages, but both groups show diminishing rates above the age of 25 as is seen also among married men (Fig. 6).

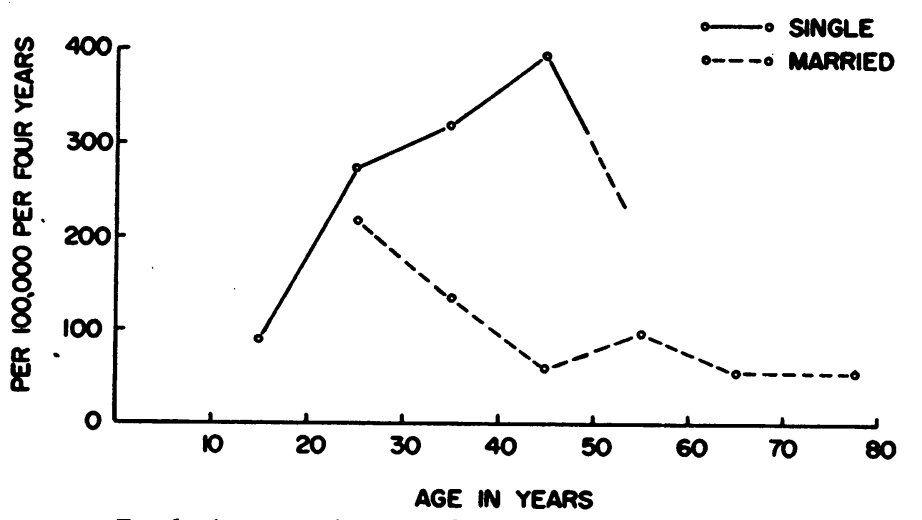

Fig. 6.-4-year prevalence rates for males by age and marital status. (Widowed, divorced, and separated not included.) 
In sharp contrast, the graph for unmarried men rises into middle age with rates well above those for married men. It is likely that the rate falls abruptly for unmarried men aged 50 and over, but the estimate of 70 per 100,000 per 4 years for the age group 50 to 69 is based on only two cases. The difference between married and single men is not attributable to referral of milder cases among the bachelors. All admissions involving bachelors and married men aged 20 to 49 inclusive were grouped according to severity of poisoning. Four bachelor admissions and five of married men were unclassifiable, leaving sixty in each group. Eight (13 per cent.) of the bachelor admissions were mild cases and ten (17 per cent.) severe or fatal, compared with twelve ( 20 per cent.) and five ( 8 per cent.) respectively for married men.

If the sharp fall in rate for bachelors after the age of 50 is confirmed, it raises several questions for longitudinal study. It is possible that the vulnerable bachelors are "slow to mature" and show patterns of behaviour (perhaps including marriage) more commonly seen in younger men. Alternatively, they may contain a group who become chronic mental hospital patients or commit suicide. A cohort phenomenon is a third possibility.

Religion and Social Class.-The distributions of these variables were not available for the 1961 Census population so it was necessary to obtain a control group. This was taken from all ORLS hospital admissions for the years 1963 and 1964 . For each case two controls were drawn at random from the appropriate quinquennial age and sex stratum. In four of the strata insufficient numbers were available so that the final comparisons were made between the 702 cases and 1,392 controls. For many reasons use of a control group of this nature is unsatisfactory and results must be viewed with caution. Religious affiliation was recorded for 604 of the cases (86.0 per cent.) and 1,296 of the controls (93.3 per cent.). The distributions of the various faiths were virtually identical in the two groups. Middleton, Ashby, and Crook (1961) found a significantly higher proportion of Roman Catholics in a hospital series of attempted suicide in Gateshead than in a sample of admissions for all causes. In the Oxford data, 13.4 per cent. of cases and $11 \cdot 2$ per cent. of controls were Roman Catholics, an insignificant difference. The higher proportions of cases unclassified is attributable to the patients who were admitted unconscious and unaccompanied and is unlikely to have biased the distribution.

With regard to Social Class it was possible to apply the Registrar General's Classification of Occupations to 447 cases (64 per cent.) and 900 controls (67 per cent.). Married women were allotted according to husband's occupation, and students and members of the armed forces were omitted from both groups. Table $\mathrm{V}$ shows a shift towards Classes IV and V in the distribution of cases compared with controls for both sexes, but application of the Kolmogorov-Smirnov two-sample test (Siegel, 1956) indicates that the trends are not statistically significant $(\mathrm{P}>0 \cdot 05)$.

DAY OF ADMISSION.-Some clinicians consider that admissions for overdose occur more frequently at weekends. Table VI (overleaf) lends some support to this view for females but not for males. There were more female admissions on Saturdays and Sundays than on weekdays, although the difference is not quite significant statistically (by two-tail test $0 \cdot 10>$ $P>0.05)$. The lack of a similar effect for males suggests that it is not ascribable to variation in hospital referral. The trend in females is seen in all marital status groups.

TABLE V

SOCIAL CLASS DISTRIBUTIONS OF CASES AND CONTROLS, BY SEX

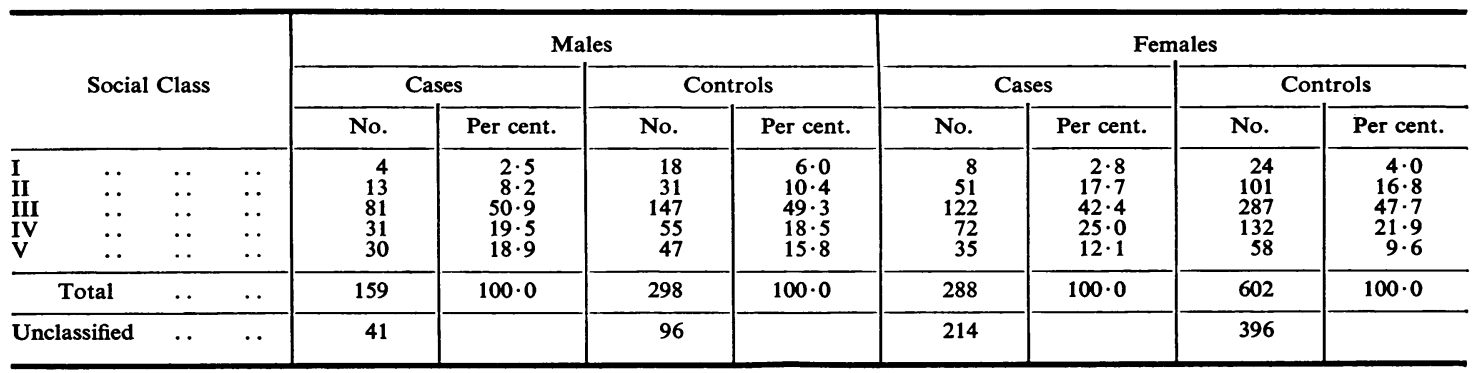


TABLE VI

DAY OF WEEK OF ALL ADMISSIONS, BY SEX

\begin{tabular}{ll|c|c|c}
\hline \multirow{2}{*}{ Day of Week } & \multicolumn{3}{c}{ Number of Admissions } \\
\cline { 3 - 5 } & & Male & Female & Total \\
\hline Sunday .. &. & 33 & 84 & 117 \\
Monday & $\ldots$ & 34 & 76 & 110 \\
Tuesday & $\ldots$ & 32 & 79 & 111 \\
Wednesday & $\ldots$ & 23 & 72 & 95 \\
Thursday & $\ldots$ & 26 & 77 & 103 \\
Friday .. & $\ldots$ & 40 & 67 & 107 \\
Saturday &. & 30 & 94 & 124 \\
\hline \multicolumn{1}{c|}{ Total } & $\ldots$ & 218 & 549 & 767 \\
\hline
\end{tabular}

AReA of Residence.-The Local Authority area in which the patient was living was known in all cases. In terms of urban/rural differences, these areas fall into four groups, viz. Oxford County Borough, the seven market towns, the three rural districts adjoining Oxford and supporting an urbanized population in the suburbs and dormitory villages of the City ("fringe rural"), and finally the three rural districts not adjoining Oxford. 4-year prevalence rates corrected for age and sex for these different regions are shown in Table VII and suggest an urban/rural gradient of diminishing prevalence. The two sexes show a similar regional variation but it is more marked in males, so that the male/female ratio increases with the overall rate. There is no consistent trend of severity with the gradient of prevalence; the rural areas have the lowest proportion of mild cases ( 18.5 per cent.) and the fringe rural the highest $(26 \cdot 7$ per cent.). Table VIII compares the mean annual prevalence rates for the first and second halves of the study period by sex and area of residence. The constancy of the male rates in urban areas contrasts with the other groups but the confidence limits are wide. The rural areas showed greater proportional increments than the urban and this difference was too great to be accounted for by the age structures of the population involved.

TABLE VII

AGE STANDARDIZED 4YEAR PREVALENCE RATES PER 100,000 , BY REGION AND SEX

\begin{tabular}{cc|c|c|c}
\hline \multicolumn{2}{c|}{ Region } & Males & Females & All Persons \\
\hline Oxford C.B. & $\ldots$ & 203 & 403 & 299 (17) \\
Small towns & $\ldots$ & 139 & 299 & 216 (14) \\
Fringe rural & $\ldots$ & 106 & 270 & 186 (13) \\
Rural.. & $\cdots$ & 65 & 232 & 148 (12) \\
\hline
\end{tabular}

Standardized to the Oxford C.B. mid-period population. Figures in brackets are standard errors.

The rate of 75 per 100,000 per year in Oxford C.B. in 1962 to 1963 may be compared with figures derived from data published for two other British
TABLE VIII

MEAN CRUDE ANNUAL PREVALENCE RATES PER 100,000, BY REGION, BIENNIAL PERIODS, AND SEX

\begin{tabular}{|c|c|c|c|c|c|c|}
\hline Region & Sex & & 196 & $52 / 3$ & 196 & $1 / 5$ \\
\hline \multirow[t]{2}{*}{ Oxford C.B. } & $\begin{array}{l}\text { Male } \\
\text { Female }\end{array}$ & $\cdots$ & $\begin{array}{l}50 \\
98\end{array}$ & $\begin{array}{r}(7) \\
(10)\end{array}$ & $\begin{array}{r}51 \\
111\end{array}$ & $\begin{array}{l}\text { (7) } \\
\text { (10) }\end{array}$ \\
\hline & All Persor & ns & 75 & (7) & 82 & (6) \\
\hline \multirow[t]{2}{*}{ Small towns } & $\begin{array}{l}\text { Male } \\
\text { Female }\end{array}$ & $\cdots$ & $\begin{array}{l}33 \\
80\end{array}$ & $\begin{array}{r}(7) \\
(11)\end{array}$ & $\begin{array}{l}34 \\
93 \\
\end{array}$ & $\begin{array}{r}(7) \\
(12)\end{array}$ \\
\hline & All Perso & ns & 56 & (7) & 63 & (7) \\
\hline \multirow[t]{2}{*}{ Fringe rural } & $\begin{array}{l}\text { Male } \\
\text { Female }\end{array}$ & $\cdots$ & $\begin{array}{l}13 \\
56\end{array}$ & $\begin{array}{l}\text { (4) } \\
(8)\end{array}$ & $\begin{array}{l}30^{*} \\
94^{*}\end{array}$ & $\begin{array}{r}\text { (5) } \\
\text { (10) }\end{array}$ \\
\hline & All Perso & ns & 33 & (4) & $60^{*}$ & (5) \\
\hline \multirow[t]{2}{*}{ Rural } & $\begin{array}{l}\text { Male } \\
\text { Female }\end{array}$ & $\begin{array}{l}\cdots \\
\cdots\end{array}$ & $\begin{array}{l}11 \\
47\end{array}$ & $\begin{array}{l}\text { (4) } \\
\text { (9) }\end{array}$ & $\begin{array}{l}25 \\
62\end{array}$ & $\begin{array}{r}(6) \\
\text { (10) }\end{array}$ \\
\hline & All Perso & ons & 30 & (5) & 45 & (6) \\
\hline
\end{tabular}

Figures in brackets are standard errors.

- Increment significant $(P<0.05)$.

urban areas, Sheffield in 1960 to 1961 (Parkin and Stengel, 1965) and Edinburgh in 1962 to 1963 (Kessel and others, 1963; Kessel, McCulloch, Hendry, Leslie, Wallace, and Webster, 1964; Kessel, 1965, 1966). Prevalence rates based on hospitab admissions and the population of all ages for these areas were 55 and 97 per 100,000 per year res: pectively. When standardized for age and sex and adjusted for the proportions of cases seen at hospital but not admitted, the difference between the Oxford and Edinburgh rates falls just short of statistical significance, but the Sheffield rate is significantly lower than both $(\mathrm{P}<0.05)$. It is likely that part, at least, of these differences is methodological in origin.

LENGTH of Stay IN Hospital.- The mean length of stay for all admissions was 3.3 days, the modal was one day. Over the 4 years there was a trend towards earlier discharge. Thus the proportion discharged in 2 nights or less rose from 49 per cent. in $1962 / 3$ to 60 per cent. in $1964 / 5$.

DEATHS.-The death certificate data collected by ORLS 1962-5 showed a mean annual rate of $\bar{N}$ suicide (all methods) of eleven per 100,000 for $\sigma$ males and seven per 100,000 for females. There $\tilde{O}$ was an insignificant fall in rate for both sexes $\underset{\omega}{N}$ between the first and second halves of the period. The rates increased with age for both poisoning 0 and other cases and were higher in urban than in rural districts.

There were eight deaths in hospital following the 767 admissions in the present study, a mean 
fatality rate of 10.4 per thousand. The number is too small for useful analysis in terms of age or year of admission. A further sixty suicidal deaths from poisoning occurred without admission to hospital, about 60 per cent. of them due to gassing. There was no relationship between annual death rates from suicidal poisoning and frequencies of hospital admissions for self-poisoning. This suggests that the effectiveness of methods of detection and treatment is increasing with the true rate of selfpoisoning, or that the two groups differ epidemiologically. Their different sex ratios suggest the second view, but the difference in age distributions may merely reflect variation in fatality and type of poisoning with age. Stengel and Cook (1958) have reviewed some clinical evidence for an aetiological difference between suicide and attempted suicide. It is important to settle these questions before adopting the suggestion of Kessel (1965) to make drugs such as aspirin more difficult to obtain, as this might increase the frequency of more dangerous forms of self-poisoning.

DisPosal. -34.4 per cent. of surviving admissions were transferred as in-patients to mental hospitals. This proportion was identical in the first and second halves of the period. In a further 49.6 per cent., the patient was seen by a psychiatric registrar, S.H.M.O., or consultant before discharge, and an additional 5.2 per cent. were given an appointment at a psychiatric out-patient clinic but were not seen there before discharge. In only 10.8 per cent., therefore, was no provision made for obtaining a psychiatric opinion. This proportion showed no trend over the 4 years.

\section{Discussion}

Most previous studies of self-poisoning have been clinically rather than epidemiologically orientated. This stems from psychiatrists' regarding the poisoning merely as a non-specific sign of a variety of underlying mental and social disorders. There are two considerations, however, which suggest the investigation of self-poisoning as an epidemiological entity per se. First, the reliability of psychiatric diagnoses, even under optimal conditions (Kreitman, Sainsbury, Morrissey, Towers, and Scrivener, 1961), is too low for most epidemiological purposes. Secondly, it may be that cultural factors are at least as important in determining the frequency and distribution of self-poisoning as individual psychopathology. If self-poisoning is largely a fashion, attention may be more profitably directed to its "secondary prevention" (Morris,
1964) than to the "primary prevention" of the stresses which precipitate it. It may be possible to replace the fashion by one less dangerous and less consuming of medical beds.

The present survey is restricted to hospital admissions, although these probably do not comprise an exclusive or exhaustive epidemiological grouping. To justify this approach as a practical measure, it is desirable, though not essential, to be able to show that self-poisoning has some regularities in its distribution when different areas within the same culture are compared. Data comparable with the present study are sparse but encouraging. The age and sex variations and the high proportion of divorced persons are similar to those found by Kessel (1965) in Edinburgh, as is the variation with age in the type of poison used. The data of Parkin and Stengel (1965) from Sheffield are not sufficient to permit detailed comparison.

It is important to consider in what ways the results of the present study may have been distorted by the methods of collection and analysis of the data. There is no direct means of checking the completeness of the ORLS hospital admission data, but indirect means suggest that information on about 94 per cent. of admissions is received (Acheson and Barr, 1965). The boundaries of the ORLS area are well within the catchment area of the co-operating hospitals, so there is no significant loss of cases to hospitals outside the study. The retrieval rate of hospital notes was gratifyingly high, only 1 per cent. of admissions having to be excluded on account of non-retrieval. Cases admitted directly to mental hospitals might be missed if the self-poisoning was not recorded in the diagnostic summary. Parkin and Stengel (1965) considered that in Sheffield 9.4 per cent. of hospital admissions for "attempted suicide" were directly into mental hospitals. The experience in Oxford is that such admissions may occur after self-injury but rarely after self-poisoning. This reflects the awareness by general practitioners and psychiatrists of the possible dangers of delayed effects from poisoning.

A potential source of error in the analysis was introduced in the exclusion of the 51 cases of accidental self-poisoning. These contained a high proportion of elderly persons and one is known to have committed suicide shortly after his "accidental" coal-gas poisoning. The calculated rates for the older age groups may be falsely low, therefore, and a secondary rise in rate for the elderly may have been obscured. Inclusion of suicidal poisoning deaths outside hospital does not produce such a rise, merely setting the age-specific curves of Fig. 4 at a higher level in the later decades. 
The epidemiological pattern of self-poisoning will be the result of individual susceptibility and cultural influence. Variation in either or both may produce high prevalence groups within the population. The delineation of such groups is the necessary initial step in the search for the relevant sources and mechanisms of cultural influence. A prime need is to know if the "mass media", newspapers, films, radio, television, and "pop" music, have a significant effect in spreading the fashion or whether it is communicated mainly by contagion within cultural sub-groups. The possible influence of publicized cases of self-poisoning in producing fluctuations in admission rate in Oxford has already been alluded to and merits further examination. The present study has also indicated variations in prevalence or admission rates with age, sex, marital status, year, and area, and possibly with day of the week for females. It suggests that young men and women, married teenage girls, bachelors aged between 30 and 50 , and divorced persons constitute high prevalence groups. It also shows a varying pattern of secular increases in rates with sex, age, and area. One would like to make firm interpretations of these results without further investigation. Unfortunately, it is uncertain to what extent they reflect true differences in population behaviour or in the referral practice of family doctors. Parkin and Stengel (1965) deduced from postal questionnaires that general practitioners in Sheffield treated about 20 per cent. of the cases of selfpoisoning they saw without referral to hospital. This estimate was based on only a 66 per cent. response rate, however, and in view of the low prevalence rate for this city the finding may not be of general applicability. There are no estimates for other areas and it is not known how the patients treated at home differed from those sent to hospital. In the present study an attempt has been made to detect differences in referral by variation in the proportions of mild and severe cases. With the possible exception of the rural areas, the results have been negative, but the method of analysis is crude and its interpretation is based on the questionable assumptions that the distribution of severity grades in the total cases seen by general practitioners is independent of the overall rate and of the variable being studied. An important factor in referral is likely to be the local availability of suitable hospital beds. A study of the ORLS obstetric data (Acheson and Evans, 1964) demonstrated a probable effect on the proportion of deliveries occurring at home for all categories of obstetric risk. Similar influences are to be expected on admissions for self-poisoning, and although likely to be most prominent in urban/rural comparisons may have effects when other variables are considered. The data on suicidal deaths outside hospital are not sufficient to determine whether distance from hospital influenced fatality.

Taking the results of this study at their face value, it would be easy to speculate on the relative importance of susceptibility and cultural influence in producing the observed variations in prevalence, but such speculations should take the form of verifiable hypotheses rather than clinically reasonable assumptions. One important feature stands out; there can be little doubt that self-poisoning is increasing in frequency. It is not possible to attribute the 63 per cent. increase in annual prevalence rate from 1962 to 1965 (Table II) to any or all of the sources of error discussed above. Although the rate of increase is lower in urban than in rural areas, the implication is that self-poisoning will cause increasing pressure on the emergency medical 9 services. It has recently been authoritatively stated that self-poisoning is not a "new" fashion (Brit. med. J., 1965). It would be unfortunate if this pronouncement led to complacency in the face of an epidemic. There is an urgent need for epidemiologically-orientated studies with general practitioneg co-operation.

\section{Summary}

Using the data of the Oxford Record Linkage Study, which permit computation of specific rates for a known population at risk, an epidemiological survey has been made of hospital admissions for acute deliberate self-poisoning over a 4-year period. A 63 per cent. increase in the annual prevalence rates occurred from 1962 to 1965. A "seasonal" variation was seen which may be attributable, at least in part, to publicized cases of self-poisoning. The study shows higher rates in females than in males and that peak rates for both sexes occur in early adult life. Proportionately greater increases during the study period occurred for men over $\mathbf{4 0}$ and for women under 40 years old. Very high rates are seen for married females under age 20 and for divorced persons, and relatively high rates for bachelors aged 30 to 50 . There is possibly a preponderance of female admissions at week-ends. A diminishing gradient of prevalence from urban to rural areas of residence was found, but the increase in prevalence over the study period was 0 greater in rural areas. Problems in interpretation of these results are discussed in the context of a $\stackrel{\mathscr{P}}{?}$ search for sources and mechanisms of cultural 70 determination of self-poisoning. A need is urged 
for epidemiological studies aimed at devising preventive measures.

I am very grateful to Dr E. D. Acheson, Medical Director of the Oxford Record Linkage Study for providing the data for this paper and for his encouragement and advice. Thanks are due also to the Records Staff of the United Oxford Hospitals and Oxford Regional Hospitals for their co-operation in providing the hospital notes, and to Miss C. J. Cavender for assistance in the analysis.

\section{REFERENCES}

Acheson, E. D. (1964). Brit. J. prev. soc. Med., 18, 8. and Barr, A. (1965). Ibid., 19, 182.

— and Evans, J. G. (1964). Proc. roy. Soc. Med., 57, 269.
Brit. med. J. (1965). Leader, 2, 1323.

Kessel, N. (1965). Brit. med. J., 2, 1265, 1336. (1966). Personal communication.

-, McCulloch, W., and Simpson, E. (1963). Brit. med. J., $2,985$.

, Hendry, J., Leslie, D., Wallace, I., and Webster, R. (1964). Scot. med. J., 9, 333.

Kreitman, N., Sainsbury, P., Morrissey, J., Towers, J., and Scrivener, J. (1961). J. ment. Sci., 107, 887.

Middleton, G. D., Ashby, D. W., and Clark, F. (1961). Practitioner, 187, 776.

Morris, J. N. (1964). "Uses of Epidemiology", 2nd ed. Livingstone, Edinburgh and London.

Parkin, D., and Stengel, E. (1965). Brit. med. J., 2, 133.

Siegel, S. :(1956). "Nonparametric Statistics for the Behavioral Sciences". McGraw-Hill, New York.

Stengel, E., and Cook, N. G. (1958). "Attempted Suicide". Chapman and Hall, London. 